\title{
A grande bibliologia: notas epistemológico-históricas sobre a ciência da organização dos saberes
}

\author{
The great bibliology: Historical epistemology notes \\ on science of knowledge organization
}

Gustavo Silva SALDANHA ${ }^{1}$

\section{Resumo}

A proposta do trabalho, sob a via metodológica de uma epistemologia histórica da organização dos saberes, de fundo diltheyano, é discutir alguns aspectos preponderantes da Bibliologia, tomada como macrossaber, a partir, centralmente, dos discursos de Gabriel Peignot, Paul Otlet e Robert Estivals. É objetivo do estudo perceber tal "epistemologia" como uma das pioneiras na tentativa de sustentação de um discurso científico para o que hoje é tratado como epistemologia dos estudos informacionais, ou epistemologia informacional ou, ainda, epistemologia da Ciência da Informação. Especificamente objetiva-se aqui discutir a relação da Bibliologia entre Peignot e Otlet e sua manifestação no "Iongo século XIX", pautado na cultura científica, racional e sistemática, e na consagração da epistemologia como reflexo do conhecimento acadêmico-empírico. Como verticalização, o estudo adentra a discussão sobre a elaboração científica do conceito de "livro" e sua prioridade na formulação da Bibliologia entre Gabriel Peignot e Paul Otlet.

Palavras-chave: Bibliologia. Epistemologia informacional. Filosofia da ciência da informação. História da ciência da informação. Livro.

\begin{abstract}
Based on the methodology of the historical epistemology of knowledge organization with a Dilthyean approach, the aim of the study is to discuss some prominent aspects of Bibliology, considered as macroknowledge, based on the discourses of Gabriel Peignot, Paul Otlet and Robert Estivals. The main objective was to consider "epistemology" as the pioneer in the endeavor to support scientific discourse that is now called epistemology of informational studies, informational epistemology, or epistemology of Science Information. More specifically, the objective is to discuss the relationship of Bibliology with Peignot and Otlet and its expression during the "long nineteenth century", based on scientific, rational and systematic culture and the acclaim of epistemology as it reflects academic-empirical knowledge. From a vertical perspective, we discuss the scientific concept of "book" and its importance for the development of Bibliology for Gabriel Peignot and Paul Otlet.
\end{abstract}

Keywords: Bibliology. Informational epistemology. Philosophy of information science. History of information science. Book.

\section{Introdução}

O desejo de uma panciência para a informação (esta abordada como matéria, como processo cognitivo ou como elaboração sociocultural), sustentado por três argumentos convergentes nos anos 1960 - a multiplicidade da informação como conceito; a interdisciplinaridade prevista em sua apropriação; a urgência sócio-histórica de uma epistemologia aberta para sua análise no âmbito da sociedade técnico-neoliberal em

\footnotetext{
1 Universidade Federal do Rio de Janeiro, Programa de Pós-Graduação em Ciência da Informação, Coordenação de Ensino e Pesquisa. R. Lauro Muller, 455, 40 andar, Sala 401, 22290-160, Rio de Janeiro, RJ, Brasil.E-mail:<saldanhaquim@gmail.com>.

Recebido em 11/2/2015, reapresentado em 9/9/2015 e aceito para publicação em 16/10/2015
} 
ascensão - não pode ser reconhecido como um desiderato novecentista. Antes, seja pela via conceitual das noções de bibliographie e (posteriormente) documentation no âmbito francófono, seja pela via das noções de bibliography e library science no âmbito anglófono, a procura por uma ciência geral da organização dos saberes já estava demarcada no século XIX, coincidindo com o desenvolvimento das ciências do homem.

No entanto, se as noções de documentation e library science se emanciparam como conceitos, instituições, ações e, posteriormente, ciências, entre o Oitocentos e o Novecentos (caso controverso no contexto da bibliography britânica e da bibliographie francesa, considerando as tradições nacionais de elaboração de cada saber), outra noção, não menos importante, se estabeleceu como candidata a conceito central e categoria-mor do que se passaria a tratar por "estudos informacionais".

No jogo de palavras que ora se interpõe política ou epistemologicamente no contexto de nossas ações, que em português responderiam por Biblioteconomia, Bibliografia, Documentação e Ciência da Informação (nomes amplamente adotados na paisagem de escolas, institutos, centros e outras organizações ao longo do século XX e na atualidade dedicadas ao trato conceitual e aplicado da informação), encontra-se como integrante outra noção não menos histórica e não menos inventiva. Trata-se da construção emancipatória do conceito de bibliologia e da ciência tratada por Bibliologia ou, ainda, por Ciências Bibliológicas, como é o caso de seu vasto e aprofundado aparecimento no léxico de Otlet (1934), em seu Traité de Documentation.

A proposta deste estudo, sob a via metodológico-teórica de uma epistemologia histórica, de fundo diltheyano, é discutir alguns aspectos preponderantes da Bibliologia, tomada como macrociência da Organização dos Saberes entre Peignot e Otlet, ou seja, dois de seus momentos de maior produção argumentativa. É, pois, objetivo deste estudo perceber tal epistemologia como pioneira na tentativa de sustentação de uma epistême geral para o que hoje se trata por estudos informacionais.

A base do pensamento de Dilthey (2010) faz-se aqui presente na definição tanto de um reconhecimento epistemológico da condição de independência das ciências humanas, quanto de uma procura metodológica para demarcação das distinções desse saber. Dilthey (2010, p.19) leva a definir o escopo do mundo sensível como a singularidade antevista pelas Ciências Humanas, ou seja, um certo "reino próprio de experiências que possui o seu material e sua origem na vivência interna, e que, por conseguinte, é naturalmente o objeto de uma ciência empírica particular". À procura de um lócus para a Ciência da Informação no longo e aberto processo de construção das Ciências Humanas, a visão diltheyana remonta à necessidade permanente de um reconhecimento de tais modelos e modos epistêmicos como filhos da "práxis da vida", ligados às "exigências de formação profissional", cujos conceitos e regras são encontrados, a princípio, nas próprias funções sociais (Dilthey, 2010, p.34).

É nesse sentido que se antevê, na relação estabelecida em uma epistemologia histórica - ou seja, na historicidade do pensamento e em sua práxis no espaço-tempo -, a posição de um certo fazer-saber tratado aqui como "organização dos saberes", marca da construção de uma epistemologia. Adota-se a expressão como mecanismo teórico exatamente para responder à questão epistemológico-histórica que interessa a este estudo. Seguindo uma trajetória reflexiva, procura-se afastar a pesada carga semântica dos termos "conhecimento" e "informação", que, na visão do autor deste estudo, trouxeram mais dificuldades do que possibilidades de esclarecimento de compreensão epistemológica dentro da Ciência da Informação (Cl). O afastamento desses conceitos (aplicados em expressões como "organização da informação" e "organização do conhecimento") para apresentar a experiência histórica da práxis do campo, tratado a partir do objeto-nuclear "organização dos saberes", permite que se chame a atenção para a fundamentação de uma filosofia que cuida da gramática geral e das gramáticas específicas das práticas orientadas para a ordenação, guarda e disseminação de tudo aquilo que permite ao homem refletir sobre sua própria experiência sociocultural.

Distanciamo-nos, fundamentalmente, a [sic] "pretensão científica", postulada pelo discurso epistemológico que tenta "fundar" uma "ciência para informação", nos anos 1960, estruturada em um positivismo tardio, que teria por norte a "comunidade científica" como"modelo" de comunidade. Com a noção de "conhecimento"aplicada ao nosso objeto múltiplo - "organização" - perce- 
bemos a extensão e a manutenção do significado de "conhecer" como aquilo que provém da objetividade científica moderna, refratária às demais comunidades produtoras de "conhecimento", como também aos métodos que não podem ser empiricamente demonstrados. Com o distanciamento da noção de "informação", nos afastamos da noção tradicional de "tecnologia" da Cl, também sustentada por um projeto positivista-lógico e de uma polissemia incontrolável dos usos do termo "informação" em nossos estudos (Saldanha, 2008, p.50).

Para tal empreendimento, coloca-se aqui em discussão a questão da linguagem, como pressuposto para o desenvolvimento bibliológico em um espaço-tempo epistemológico-histórico. Mais especificamente, ao pontuar a Bibliologia como um ramo das ciências humanas e, propriamente dizendo, um ramo das ciências da linguagem (antes das ciências predicadas como "sociais"), procura-se demonstrar a intrínseca relação entre Retórica, Filologia e os estudos bibliológicos, bem como a relevância da noção de simbolismo nesse desdobramento dos domínios de reflexão e crítica da linguagem.

Essa margem está claramente manifestada em Peignot (1802a, 1802b) e em Paul Otlet: aqui se encontra a forte relação entre pensamento, linguagem e registro do conhecimento (evocado pelo conceito de livro), colocada como centralidade da macro-epistême que se quer constituída no século XIX. Nas palavras do advogado belga, "[...] o livro torna-se uma forma de elaboração do pensamento humano, a concretização deste pensamento em seu mais alto grau. A Bibliologia já não se limita a ser tecnológica. Torna-se psicológica, pedagógica, sociológica" (Otlet, 1934, p.93, grifo e tradução minha)².

O (re)encontro com Paul Otlet provocado pelos neodocumentalistas (apartados do pensamento francófono em grande medida), como Frohmann (2004), tecido nas últimas décadas, intensifica essa relação, porém sob um conceito que se desdobra da noção de livro, ou seja, documento. Interessa, antes do documento, no entanto, a profundidade socioepistêmica do decurso histórico da noção de livro, transmutada em conceito entre (a) o processo milenar de constituição de seu metaforismo e (b) a aplicação racional e sistemática de seu uso entre os séculos XVIII e XIX, desenhada reflexivamente na tentativa de construção científica da "Grande Bibliologia" a partir do projeto enciclopédico, de inspiração francis-baconiana, de Peignot (1802a, 1802b), propagado também em Estivals (1992, 2010).

O conceito de "bibliologia" pode ser recuperado em diferentes autores e tradições; sua construção não é exclusiva do discurso francófono. Fontes como Finó (1954) e Martinez de Sousa (2004) são demonstrações de sua pluralidade. Sua aplicação vai da discussão macroconceitual - o discurso sobre uma ciência - ao debate empírico sobre o uso do termo relativo a um conjunto de técnicas. A reflexão epistemológico-histórica a seguir procura concentrar-se, no entanto, nos modos de construção desse conceito no panorama epistemológico, ou seja, na tentativa de invenção de uma dada ciência e de demarcação de seus regimes de cientificidade.

\section{A invenção da bibliologia}

A invenção "científica" do simbólico no âmbito da organização dos saberes, ou seja, das artes antientrópicas denominadas no Novecentos como informacionais, se dá no século XIX. Essa caracterização, no entanto, é fruto de mais de dois milênios de construção: as aproximações hodiernas entre "informação e poder", "documento e inteligência", "biblioteca e sabedoria" são fruto do simbolismo que é edificado em torno do objeto livro - ou, simplesmente, nas cercanias dos radicais grego e latino, biblión e liber, respectivamente. Essa construção tem seu solo no nascimento literário - ou apenas o "solo na linguagem" - da bibliologia como, primeiramente, uma técnica ou saber "primitivo", do mesmo modo que se dá com a Retórica e a Filologia: a"questão homérica"inaugura um saber que, de um lado, adora o discurso e, de outro, preserva-o como bem comum amado (filia), lutando contra sua dispersão, seja enquanto continente, seja enquanto conteúdo.

\section{Os caminhos da utopia: a estrada do Oitocentos}

Erudito, bibliógrafo, bibliófilo, interessado nos mais diferentes domínios, Gabriel Peignot, nascido em

\footnotetext{
${ }^{2}$ Ainsientrevu, le livre devient le moyen d'elaboration dela pensée humaine, la concrétion de cette pensée à ses degrés les plus élevés. La Bibliologie ne se borne plus à être technologique. Elle devient, on l'a vu, psychologique, pédagogique, sociologique" (Otlet, 1934, p.93)
} 
1767 e falecido em 1849, escreveu ensaios sobre a liberdade de imprensa no período medieval e no contexto do nascimento da modernidade. Seu Dictionnaire Raisonné de Bibliologie, de 1802, propõe-se constituir uma obra didática para os estudos bibliológicos, incluindo a explicação dos principais conceitos do vocabulário que gira em torno do "livro", passando pela indicação de bibliotecas, arquivos, museus, chegando até a exposição dos sistemas bibliográficos aplicáveis às instituições.

Assim como Otlet (1934), interessado em uma visão global sobre a organização dos saberes, o autor do Dictionnaire desenvolve um índice bibliográfico universal, em 1812, analisando ainda a elaboração e a apropriação dos suportes e técnicas para registro da informação, como pergaminho, papel vegetal, encadernação e litografia. Também como ocorre no pensamento do advogado belga, Peignot (1802a, 1802b) atentará para as práticas bibliológicas de maneira ampla, envolvendo os futuros domínios da Museologia e da Arquivologia, além de outros saberes, trabalhando em sua reflexão, por exemplo, com os gabinetes de história natural e física.

Como observa Couzinet (2011), Otlet (1934) recebeu influência direta do trabalho de Peignot (1802a, 1802b).

Erudito, bibliógrafo, bibliófilo, interessado nos mais diferentes domínios, Gabriel Peignot, nascido em 1767 e falecido em 1849, escreveu ensaios sobre a liberdade de imprensa no período medieval e no contexto. Seu Dictionnaire Raisonné de Bibliologie, de 1802, propõe-se constituir uma obra didática para os estudos bibliológicos, incluindo a explicação dos principais conceitos do vocabulário que gira em torno do "livro", passando pela indicação de bibliotecas, arquivos, museus, chegando até a exposição dos sistemas bibliográficos aplicáveis às instituições. O autor (tal como fará mais tarde Otlet, interessado em uma visão global sobre a organização dos saberes), também desenvolveu um índice bibliográfico universal, em 1812, em que analisa a elaboração e a apropriação dos suportes e técnicas para registro da informação, como pergaminho, papel vegetal, encadernação e litografia. Peignot (1802a, 1802b), tal qual Otlet, atentou ainda para as práticas bibliológicas de maneira ampla, envolvendo os futuros domínios da Museologia e da Arquivologia, além de outros saberes, trabalhando em sua reflexão, por exemplo, com os gabinetes de história natural e física. Por fim, assim como Otlet (1934), o olhar peignotiano considerou a "linguagem" como elemento fundamental e fundacional para a prática do organizador dos saberes: verbetes como "etimologia" e "língua" ganharam exaustividade no trabalho.

Percebe-se entre Peignot (1802a, 1802b) e Otlet (1934) o desenvolvimento de uma epistême da organização dos saberes no século XIX. No entanto, esse saber em busca de uma afirmação científica não cessa com a publicação do Traité de Documentation, de Otlet (1934).

A partir de 1968, com a Associação Internacional de Bibliologia, Robert Estivals inicia o processo de reapropriação do conceito disciplinar, tomando-o, assim como seus antecessores, como sinônimo de uma macrociência, agora identificada sob o significado de ciência da escrita e da comunicação escrita. Essa longa historicidade convoca uma análise específica da construção metacientífica do discurso bibliológico.

\section{Uma epistemologia da Bibliologia}

Reconhecida toda a potência discursiva que nasce do conceito de "livro" no Ocidente, já se teria, claramente, uma macrodisciplina no tempo, consolidada no século XIX. Em termos geopolíticos imediatos, a Bibliologia (de linhagem peignotiana) é resultado das transformações sociais do século XVIII, a saber: Revolução Francesa, Revolução Científica, Revolução Industrial, independência das colônias norte-americanas.

No âmbito da Revolução Francesa, consolidam-se os estados nacionais (impulsionando a futura formalização, tardia, da Alemanha e da Itália) e a necessidade de uma "fronteira simbólica" sob/sobre a "fronteira política" - o mapa político como aquilo que é: retórica cartográfica -, que será sustentada pelas Bibliotecas Nacionais, responsáveis consagradas pela memória bibliográfica da "cultura nacional inventada" (Saldanha, 2012).

No contexto da revolução científica, assiste-se à consagração do método indutivo, de uma física "material" e de uma empiria estrutural, como também à consolidação da especialização das ciências, com a elaboração de línguas de especialidade cada vez mais carregadas de vocabulário próprio, promovendo a necessidade de uma organização, visando à preservação e disseminação, da"cultura científica". Da mesma forma, as bibliotecas uni- 
versitárias e especializadas, como também as bibliotecas científicas (United States of America, 1876) demonstram essa condição.

No terreno da revolução industrial, os mecanismos possibilitados pelas novas tecnologias miméticas atingirão todos os domínios sociais, incluindo a produção documental e, logo, as práticas de organização dos saberes. Soma-se a esse processo a rápida urbanização provocada pela industrialização - no terreno da linguagem, iniciada com a prensa gutenbergiana -, que é fruto do e resulta diretamente no desenvolvimento de uma"cultura da linguagem registrada" (que envolveria as práticas de culto do livro, do documento e da informação). O "homem urbano" é um sujeito do discurso impresso - dos registros de nascimento aos registros de óbito, passando pela produção bibliográfica erudita desenvolvida na academia, culminando com os "descritores" dispersos na paisagem das cidades, como orientações em placas e nomenclaturas de instituições públicas e comerciais distribuídas pelas ruas.

No caso da independência das colônias americanas, tem-se a rápida apropriação e aplicação das transformações oriundas dessas três revoluções destacadas do Velho Mundo - a América como laboratório da filosofia da Revolução Francesa, da intervenção das tecnologias industriais e da construção do ideal científico -, resultando em uma tecnocultura democrática, que precisará também de uma instituição para significar sua aposta na liberdade de expressão (ideal político), acesso ao conhecimento (ideal científico) e desenvolvimento técnico (ideal industrialista). A essa instituição será dado o nome de "biblioteca pública".

Como aponta Morales López (2008), o aspecto social é preponderante para o surgimento do discurso da Bibliologia. É com a Revolução Francesa, em 1789, que nasce o modelo bibliológico liberal nacional, com foco na liberdade de ideias e de expressão. Somava-se ao ideário contextual dos fins do Setecentos, o desenvolvimento aberto de uma opinião pública, sendo o Estado responsável direto por tal fomento. O apoio à produção do livro e sua difusão, bem como das ciências e de seus canais de comunicação, fazia parte integral do projeto revolucionário.

A bibliografia nacional, a nacionalização das bibliotecas particulares e o aprofundamento nas teorias bibliográficas descritivas e classificatórias são instrumentos intelectuais e ações políticas de natureza bibliológica que demarcam a emergência de tal campo do conhecimento. O livro ainda representava, para o ideário da Revolução Francesa, a ferramenta de reflexão sobre o passado, visando orientar os rumos do Estado. Tal livro já não é mais o objeto estético de alguns momentos da Cristandade, mas o ente vivo que espelha o saber humano empírico-materialista. Essa viragem na filosofia do livro responde por outra cadeia de movimentações sociobibliológicas, como alfabetização das massas, mudança do copista para o livreiro-editor, e fortalecimento do códice como ferramenta consagrada da expressão do biblión como meio de comunicação e de expressão (Moralez López, 2008).

Tomada apenas a transformação filosófica do período em sua racionalidade ampla, diretamente ligada à revolução da ciência, encontra-se a consagração teórica do conceito de livro para além do códice, como matéria de reflexão do pensamento científico. Percebe-se que, no século XIX, as disciplinas específicas ganham a formalização conhecida no século seguinte: uma ciência para a natureza, a Física propriamente dita; uma ciência para a vida, a Biologia propriamente dita; outra para a política, a Ciência Política propriamente dita. Reunidas, todas essas abordagens resultam no livro. Essa posição é claramente marcada na visão de Stéphane Mallarmé, e o livro - antes, imagem do conhecimento filosófico pós-platônico, do conhecimento teológico medieval e do conhecimento humanista - passa a ser a imagem da ciência: para o livro, desenvolve-se, no Oitocentos, uma metaciência que é revelada em cada saber. Na visão do autor deste estudo, trata-se, antes de tudo, de uma metaciência fundada na reflexão sobre a linguagem e a isso dedicada, tendo o livro como um de seus objetos prioritários, tanto conceitual, quanto empiricamente.

\section{O livro como objeto científico}

Tomada a transformação filosófica pontual do período, reorientada para a linguagem, reencontra-se a raiz elementar do saber bibliológico tecido ao longo do tempo, junto da Retórica e da Filologia. Com a interpretação da linguagem como natureza humana, Nietzsche (1999, 2008) estabelece um ponto de partida para a revisão 
filosófica sobre a linguagem no século XIX. Do neopositivismo ao pragmatismo, grande parte das discussões em Filosofia terá relação direta ou, ainda, uma metaobservação da linguagem; em outras palavras, a Filosofia se resumiria à Filosofia da Linguagem, como é o exemplo futuro da visão do "segundo"Wittgenstein (1979).

Desse modo, no século XIX já se encontra um sistema filosófico-didático para a organização dos saberes, concentrado no objeto livro, tomado como imagem ideal do conhecimento científico, ou simplesmente do "homem ideal" do Oitocentos. Se a ciência é definida como especialidade, a especialidade que trata do livro é uma metaciência que se apropria dos demais ramos da árvore geral do conhecimento. O Dictionnaire Raisonné de Bibliologie, de Peignot (1802a, 1802b), significará a maturação desse saber - de uma epistemologia da organização dos saberes - em suas mais distintas linhas de intervenção disciplinar.

No Oitocentos encontra-se, pois, uma epistême para toda a potência do livro, a saber:

a) Uma"física do livro": ramo que vai da Glossomètre (método de comparação de línguas, visando à identificação dos elementos comuns) anotada por Peignot (1802a, 1802b) e da Bibliografia estatística desenvolvida na modernidade biblioteconômica norte-americana (United States of America, 1876), até se desdobrar posteriormente na Bibliometria otletiana e ranganathaniana e nas leis bibliométricas da Cl. Em Otlet (1934, p.12) encontra-se a significação da "Bibliologia física", tratando de elementos que atravessam matéria, escritura e tipografia, a tecnologia das artes gráficas e do catálogo bibliográfico. Por sua vez, uma física bibliológica, propriamente dita, a epistemologia da Bibliologia voltar-se-ia para a "medida do livro", resultando na futura Bibliometria (Otlet, 1934, p.13). Essa"física" compreenderia o livro como um agregado de matéria, passível de ser mensurada e comparada. Fariam parte desse complexo: a análise físico-bibliológica, a discriminação das unidades de medida, a estilística ou estudo da forma de expressão dos autores; a stichométrie, que diz respeito aos métodos métricos usados na Antiguidade e no Medievo para determinar padrões, como o comprimento de versos; a definição dos coeficientes, como formatos ou pontos tipográficos, e das frequências, como leituras de um autor, constituindo uma bibliosociométrie; b) Uma "medicina do livro": domínio que, perpassando o escopo da física bibliológica, engloba os ramos que procuram compreender a "saúde orgânica" dos artefatos da linguagem, envolvendo conservação preventiva, restauração e preservação, derivadas diretamente da Bibliofilia, como demarcado em Peignot (1802a, 1802b). Tem-se como exemplo, no autor, a indicação do conceito de bibliuguiancie, que responde pela arte de restaurar livros preciosos que sofreram algum tipo de acidente. Esse domínio reúne ainda as patologias marcadas entre homem e livro, saúde extrínseca, como a Bibliomania e outras enfermidades ligadas à apropriação do saber registrado, como seus problemas ergonômicos e oculares vinculados à relação leitor-livro (Otlet, 1934);

c) Uma "biologia"e uma "química do livro": anexas à "medicina do livro", elas cuidam de compreender a matéria de que é feito cada um dos suportes do livro, compreendendo seu ciclo de vida e as possibilidades de reconstituição de sua composição (Peignot, 1802a, 1802b; Otlet, 1934);

d) Uma "história do livro": vasto domínio que envolve a história da escritura e das formas de sua manipulação, incorporando a história das instituições que envolvem os registros do saber humano, como a história das bibliotecas, a história dos suportes e dos mecanismos de intervenção no suporte, seja para escritura, seja para sua recuperação, seja ainda para sua apropriação (Peignot, 1802a, 1802b; Otlet, 1934);

e) Uma"psicologia do livro": ramo em surgimento, esclarecido apenas no século XX por Roubakine (1998) e sua Bibliopsicologia (manifestada no livro Introdução à Psicologia Bibliológica), e por Otlet (1934), mas já aplicado como princípio terapêutico na vanguarda norte-americana, principalmente, nas práticas de formação de leitores e no futuro estudo de uso e usuários. Na visão de Otlet (1934), trata-se do estudo das relações entre autores e leitores pelo intermédio do livro, ou qualquer ferramenta que perceba ou processe a linguagem (Peignot, 1802a, 1802b; Otlet, 1934). Essas questões estão ligadas às operações de percepção, recepção e apropriação da linguagem, conforme destaca Estivals (1981) em sua releitura da Bibliologia em Peignot e Otlet. Reportando-se a Roubakine, o pesquisador francês trata o domínio como "psicologia bibliológica"; 
f) Uma "estética do livro": também denominada "teoria estética do livro", envolve ainda a história e a crítica da "arte bibliológica", que engloba a arte de criação do livro, como também o livro de arte propriamente dito. Esse amplo domínio vai das práticas de análise estética do desenho gráfico, envolvendo continente e conteúdo, ao desenvolvimento das vanguardas artísticas como "livro-objeto" e"livro de artista", isso já no século XX. Estão aqui envolvidos, por exemplo, os elementos ilustração, caracteres tipográficos, decoração e justificação (controle de margens) (Peignot, 1802a, 1802b; Otlet, 1934);

g) Uma "ciência jurídica do livro": cobre toda a legislação que está voltada ou é fundada para as práticas de relação entre homem e registros do saber, incluindo estudos de direito autoral e aqueles de autenticidade, genuinidade, plágio e censura, chegando à averiguação de práticas de furtos e desaparecimentos de itens, expressões estas bem demarcadas nos Estados Unidos no século XIX, incluindo ainda as leis sobre liberdade de imprensa, liberdade de expressão e depósito legal (Peignot, 1802a, 1802b; United States of America, 1876; Otlet, 1934);

h) Uma "economia do livro": também fundamentada claramente no pensamento norte-americano do Oitocentos, incluindo as transações dos registros do saber, precificação, expectativas, acordos, chegando até a economia simbólica das trocas dos artefatos entre instituições, estados e indivíduos, envolvendo a linha disciplinar que está manifestada em ramos do Desenvolvimento de Coleções e Administração de Bibliotecas, chegando à contemporânea Economia da Informação (Peignot, 1802a, 1802b; United States of America, 1876; Otlet, 1934);

i) Uma "administração do livro": voltada para dirigir as instituições do biblión, cobrindo todas as práticas de gestão específicas e a construção do perfil profissional do organizador dos saberes, escorrendo pela citada disciplina de Administração de Bibliotecas até as atuais práticas de gestão da informação e do conhecimento (Peignot, 1802 a, 1802b; Otlet, 1934);

j) Uma "antropologia do livro": representada pelos estudos que envolvem práticas culturais locais em torno do livro, da biblioteca e das trocas simbólicas (principalmente pela raiz filológica peignotiana e otletiana) que envolvem artefatos do conhecimento, bem como cultu- ras de apropriação do livro através da editoração e da leitura (Peignot, 1802a, 1802b; Otlet, 1934);

k) Uma"sociologia do livro": cobre, principalmente, estudos de apropriação social do livro por sociedades e as transformações causadas por essa relação, com destaque para a bibliografia britânica, já no século XIX conhecida como uma "sociologia dos livros". Envolve, por exemplo, as ideias de Roubakine sobre a diáspora do livro e o desenvolvimento da"física social do livro", já mencionada (Peignot, 1802a, 1802b; Otlet, 1934; Couzinet, 2011);

I) Uma "pedagogia do livro": com forte fundamentação nos Estados Unidos do século XIX, em Otlet (1934), toma a biblioteca como espaço educacional e correlaciona todas as práticas pedagógicas ali desenvolvidas. A linha disciplinar desse âmbito deixa um grande lastro no século XIX, indo da Referência e da Biblioteca Escolar à comunicação e divulgação científica até a Competência Informacional (Peignot, 1802a, 1802b; United States of America, 1876; Otlet, 1934);

m) "Uma ciência política do livro": responde pela construção de reflexões e projetos para expansão da publicação e acesso aos livros, bem como análise das práticas estatais de controle e disseminação das tecnologias da linguagem, em diálogo direto com os processos de institucionalização de elementos legais de circulação e uso dos livros (Peignot, 1802a, 1802b; United States of America, 1876; Otlet, 1934);

n) Uma "tecnologia do livro": tomada como o estudo das técnicas de reprodução de documentos, tão forte no Traité de Otlet como no desenvolvimento de novas técnicas. Da editoração tradicional à editoração eletrônica, à aplicação da microfilmagem na organização do saberes e à futura automação de bibliotecas, passando pelo desenvolvimento de mecanismos de fluxo informacional, como o Memex e, posteriormente, a Internet propriamente dita (Peignot, 1802a, 1802b; Otlet, 1934);

o) Uma "engenharia do livro": responde pela prática de construção do livro - a bibliopée de Peignot (1802a, 1802b) - e se volta principalmente para a aplicação de novas tecnologias de desenvolvimento dos suportes da linguagem, como o caso do microfilme e das demais formas de registros analisadas no trabalho otletiano (Peignot, 1802a, 1802b; United States of America, 1876, Otlet, 1934); 
p) E, por fim, uma "filosofia 'propriamente' dita do livro", tendo, no século XIX, não apenas bibliólogos especializados envolvidos, mas também filósofos e escritores, como Nietzsche e Mallarmé, discutindo as questões vinculadas aos fundamentos do conceito de livro (Peignot, 1802a, 1802b; Otlet, 1934).

Todos esses saberes ainda aguardam investigações precisas sobre os processos de movimentação das noções, elaboração dos métodos de aplicação, sedimentação dos conceitos, emancipação dos domínios de estudo e dispersão, ora como simples noções, ora como ou sub ou protoconceitos, ora ainda como disciplinas. É o caso, por exemplo, da "preservação", costurada entre uma Medicina, uma Biologia e uma Química de caráter bibliográfico. O que chama a atenção do pesquisador e conduz à revisão anotada brevemente é o foco em demonstrar como Paul Otlet se apoia ora em Gabriel Peignot, ora na elaboração rápida da Library Science nos Estados Unidos. Isso para fundar sua Bibliologia ou a Ciência Bibliológica geral, que faz do livro a sua grande unidade de análise e imaginação, do mesmo modo que Robert Estivals recorre a esses dois autores para construir a Bibliologia pós-1960.

\section{A bibliologia e o livro}

Na raiz da experiência do organizador dos saberes em sua luta permanente contra a entropia, muito antes da consagração do século XIX, encontram-se uma "filologia"e uma "retórica" peculiares ao seu estudo, presentes em todos os domínios acima mencionados. Essa consagração do livro como o metaobjeto por excelência, o elemento metodológico que é objeto de todas as especialidades científicas, está manifestada ao longo do século XIX e pode ser demarcada, posteriormente, entre três grandes publicações que viriam compor parte estrutural do "cânone bibliológico":

- "Dictionnaire Raisonné de Bibliologie", de Peignot (1802a, 1802b);

- "Traité de Documentation", de Otlet (1934);

- "Revue Internacionale de Bibliologia: Schéma et Schématisation", editada por Robert Estivals, a partir de 1968.
Está nessas obras, cada qual com sua ênfase, essa "árvore do conhecimento" à parte, vinculada aos saberes do livro. No entanto, existe, ainda sob as visões do Oitocentos, uma aproximação direta que coloca Peignot e Otlet em diálogo, sendo Robert Estivals fruto de um contexto com disparidades muito mais amplas na comparação entre os três momentos. Apesar da distância entre a publicação do Dictionnaire e do Traité, Otlet é um homem do século XIX que experimenta as mutações do século seguinte. Desse modo, ao se tratar do século XIX, como encaixar o pensamento de Paul Otlet presente no Traité, apenas explicitado na paisagem discursiva da organização do saberes no século XX? Algumas razões práticas podem ser apresentadas:

A primeira questão responde por um tom epistemológico justificado quanti e qualitativamente: no Traité, Otlet trabalha mais com noções bibliológicas do que documentalistas propriamente ditas, como parte da doxografia equivocadamente entendeu. Podem-se indicar como fontes documentalistas e neodocumentalistas, de um lado, Briet (1951) e Coblans (1957), e, de outro, Day (2001) e Frohmann (2009), que adotaram de maneira intensiva ou extensiva um léxico documentalista, em lugar de um vocabulário bibliológico.

A segunda pode ser respondida pela própria questão cronológica que, à primeira vista, pode causar equívocos: é reconhecido que, até a Segunda Guerra Mundial, grande parte das novidades do mundo do Oitocentos ainda está em constante atuação - e replicação. A própria Cl é um exemplo direto: se tomada como saber distinto, teria nascido nos anos 1960, exatamente nos moldes das ciências positivistas do século anterior, estruturadas no pensamento comteano. Em outras palavras, não apenas no caso bibliológico, mas também em outros cenários, o século XIX, ou as ideias e os ideais do período, pode ser colocado como "definitivamente" encerrado (se concluído, de fato, estiver) em meados do século XX, com a Segunda Guerra Mundial, que demarca também a morte de Paul Otlet, em novembro de 1944.

Por fim, por outra via de interpretação, o tempo cronológico não coincide com o tempo subjetivo de construção dos discursos. Assim como se percebe a sobreposição permanente entre a discursividade estabelecida sob as noções de "Biblioteconomia", "Documentação", "Ciência da Informação","Neodocumentação", por 
exemplo, tem-se aqui um tempo do discurso que claramente se integra ao pensamento do século XIX, apesar de tanto antecipar as transformações pós-Segunda Guerra Mundial.

Compreendido isso, o trabalho de Otlet (1934), com suas quase duas mil alusões ao termo "livro", estabelece definitivamente o cânone bibliológico e, ao mesmo tempo, sepulta a Bibliologia no discurso epistemológico da organização dos saberes. A partir de seu trabalho, fala-se mais em "documentação", e esta sempre estará colocada na polêmica com a Biblioteconomia. Esta última será tratada como Ciência da Informação e, mesmo quando se retoma o pensamento fundador dos discursos atuais, fala-se em "neodocumentação", e não em neobibliologia.

O Traitéé, desse modo, um réquiem à Bibliologia e à organização dos saberes do século XIX - não em sua intenção, que, ao contrário, indica a segunda grande fundamentação dessa ciência, mas em sua recepção, que adotou o termo "documentação" como o neologismo que fundaria um novo campo. O surgimento, em 1968, da Revue Internationale de Bibliologie: Schéma et Schématisation, parece não conseguir multiplicar o silêncio já existente do conceito quando da conclusão da obra de Paul Otlet. O Traité aponta uma necessidade bibliológica para o conceito de "homem": o espírito humano depende da construção de um pensamento bibliológico no tempo. Os livros e os documentos são, desse modo, a "memória gráfica da humanidade", o "corpo material do conhecimento", a "expressão escrita da civilização" (Otlet, 1919, p.27).

O século XIX consagra o nascimento das ciências do homem a partir da redução objetiva a um objeto irredutível de análise; chega-se ao século da consagração científica do livro. Antes, como visto, trata-se do momento em que a linguagem - principalmente no jogo disciplinar entre Retórica e Filologia, junto da Filosofia - ganha a configuração de objeto pleno. $O$ final do século anterior já revelava os indícios da transformação. Nesse contexto, aquele que, para a doxografia documentalista e neodocumentalista, deixou de ser o grande conceito de Paul Otlet - o livro - representará o conceito estrutural dessa tentativa de formalização científica, não obstante o trabalho de Day (2001) revelar, em parte, o contrário.

\section{O nome da Bibliologia}

A possível "cientificidade" do Oitocentos no campo da organização dos saberes está ligada à construção de extrema complexidade de uma ontologia do livro, que o tem como"ser"e desenvolve, a partir dele, uma "grande cadeia do ser", parafraseando Lovejoy (2005). Assim, a Bibliologia é uma grande distribuidora de formas que constituirão conceitos; e dos conceitos se constituirão disciplinas; e das disciplinas, especialidades científicas. Será essa configuração polidisciplinar, que tem a Bibliografia como teoria geral aplicada, a teia complexa de saberes que servirá como a base de fundamentação da Biblioteconomia, da Documentação e da Ciência da Informação.

E é em Paul Otlet que se encontra essa "ontologização" em sua matéria pura. É por isso que o que se trata aqui, em uma epistemologia histórica da Bibliologia em sua primeira formulação, como século XIX, tem um fim simbólico determinado - 1934, o ano de publicação do Traité.

O autor deste estudo aponta também uma datação simbólica de nascimento da Bibliologia: 1802, ano da publicação do Dictionnaire Raisonné de Bibliologie. Esta é não só uma fronteira temporal, mas uma fronteira geográfica para o pensamento bibliológico - o pensamento de origem da organização dos saberes como um saber científico distinto na paisagem do conhecimento.

No século XIX, diante da demanda científica e industrial, com a respectiva especialização dos saberes e a possibilidade mimético-linguística multiplicada cada vez mais desde a invenção da prensa, a atividade de repertoriar foi considerada um trabalho relevante para o desenvolvimento do saber (Couzinet, 2011).

Les premiers théoriciens de la science du livre et des
bibliothèques désignent leurs travaux par
'bibliographie.' C'est les cas de Jean-François Née de
la Rochelle, libraire parisien, dans son Discours sur
la science bibliographique et sur devoirs du
bibliothécaire publié en 1782 ou du Traité
élémentaire de bibliographie de S. Boulard,
imprimeur-libraire, paru em 1804-1805 ou encore
du Cours élémentaire de bibliographie de C.-F.
Achard, bibliothécaire, paru 1806-1807. Ils étudient
le livre dans ses divers aspects: histoire de la
typographieetdespremiers imprimeurs, catalogage
et classification, mesures de conservation, droits et

TransInformação, Campinas, 28(2):195-207, maio/ago., 2016 
devoirs des bibliothécaires. De même, après la Révolution française, afin d'aider à la tache immense de recensement et de catalogage des biens nationalisés, le chef du Bureau bibliographique de Paris, Urbain Domergue, et Henri Grégoire, évêque constitucionel de Blois, avaient redigé chacun un rapport dans lequel les instructions et les recommandations montraient bienquetechnique bibliographique et science du livre étaient inséparables (Couzinet, 2011, p.178, grifo meu).

É nesse contexto que aparece ogrande Dictionnaire de Peignot (1802a, 1802b). Nesse sentido,

Paul Otlet reprendra la définition de Peignot en
posant la bibliologie comme science générale
embrassant l'ensemble systématique classé
des donnés relatives à la production, la
conservation, la circulation et l'utilization des
écrits et des documents de toute espèce et
comme science théorique, comparative,
génétique et abstraite, embrassant tous les
livres e toutes les espèces et toutes les formes
de documents (Couzinet, 2011, p.179, grifo
meu).

Gabriel Peignot, segundo Couzinet (2011), foi quem introduziu a distinção entre Bibliologia e Bibliografia. A primeira está centrada nos aspectos teóricos da ciência do livro e no estudo dos resultados das ciências do espírito ou dos conhecimentos filosóficos, históricos, literários. Já a Bibliografia é tida como um dos ramos bibliológicos voltados aos aspectos técnicos da elaboração de repertórios de livros. Em outras palavras, "bibliographie est la partie descriptive et la bibliologie la science qui interroge les phénomènes liés à l'écrit" (Couzinet, 2011, p.179). Assim, é entre Peignot (1802a, 1802b) e Otlet (1934), via Bibliologia, que se dá a construção da primeira tentativa de reflexão epistemológica da organização dos saberes.

Na visão do Dictionnaire, a Bibliologia ou ciência dos livros está envolvida com as partes essenciais que compõem esse saber: (1) a Glossologia ou ciência das línguas; (2) a Diplomática ou ciência das escrituras; (3) a Bibliopée ou composição dos livros; (4) a Tipografia ou ciência da impressão; (5) a Bibliopolie ou ciência da livraria (librairie); (6) a Bibliografia ou conhecimento dos livros; e (7) a História literária universal (Peignot, 1802a, 1802b).

Em seu discurso preliminar, Peignot (1802a) reconhece a Bibliologia como aquela ciência que
Embrassant l'universalité des connaissances humaines, s'occupe particulièrement de leurs principes élémentaires, de leur origine, de leur histoire, de leur division, de leur classification et de tout ce qui a rapport à l'art de les peindre aux yeux et d'en conserver le souvenir par le moyen de signes, soit hiéroglyphiques ou épistoliques, soit manuscrits ou imprimés. On voit, par cette définition, que la Bibliologie peut être considérée comme une espèce d'encyclopédie littéraire méthodique [...] (Peignot, 1802a, p.viii).

Como o Dictionnaire se propõe a ser um Manuel du Bibliothécaire, são indicadas as disciplinas-verbetes que virão compor o saber bibliológico a partir de um itinerário de consulta. Esse percurso deve tomar os seguintes passos graduais de acesso: (1) Bibliografia e Bibliotecário; (2) Línguas, que envolverá a passagem pelos verbetes Alfabeto, Diplomática e Letras, por exemplo; (3) Escritura, que envolverá a visita aos verbetes Caligrafia, Paleografia, Hieróglifos, Abreviações, Pergaminhos e Palimpsesto, dentre outros; (4) Arte da fala e da escrita em sua reflexão histórica (aqui se devem consultar os verbetes Filosofia e História da Literatura), Biblioteca, Academia, Universidade e Museu; (5) Tipografia, que envolverá verbetes como Impressão, Caracteres, Impressor, Ortografia; (6) Livraria, que trata da economia dos livros; (7) Bibliografia, que trata do conhecimento dos livros e reúne os verbetes Livros, Edições, Formatos, Bibliomania, Bibliofilia, Bibliophates, Gabinete de história cultural, Medalhas, Gravuras, Esculturas, Arqueologia e Pinturas; (8) Sistemas bibliográficos.

Percebe-se claramente, na definição da ciência que se diz bibliológica, sua relação intrínseca com a linguagem, especificamente com os fundamentos da Retórica e da Filologia. De um modo geral, enquanto saber específico do livro, a Bibliologia ocuparia o papel de matriz de tudo aquilo que envolve o conhecimento desse objeto, tratado por livro.

Nota-se igualmente que, dentro de um decurso epistemológico-histórico, os discursos manifestados sob os termos "documentação" e "ciência da informação" parecem ter guardado certa afinidade com a Bibliografia mas não a Bibliografia em sentido amplo, de fundo teórico, e, sim, uma abordagem bibliográfica aplicada. Afasta-se, pois, a construção de um ponto de vista global sobre a cientificidade de um campo em construção dentro das 
ciências humanas, com fortíssima tendência orientada para a linguagem, marca da Bibliologia em seu sentido maior.

\section{O nome do livro}

Capítulo elementar na história do homem, o livro representa uma condição para a construção de qualquer reflexão filosófica, seja como instrumento, seja como conceito integrador. Nesta revisão, é forçoso determinar que todas as visões consagradas ao livro estão necessariamente circuladas por um caráter simbólico. É é esse caráter que resultará na consagração científica do livro no século XIX: a ciência não apenas se apropria do livro como metaobjeto - a Bibliologia como epistemologia geral da Organização dos Saberes -, mas o livro é o instrumento estrutural da ciência, seja em seu formato áureo, o códice, seja em seus substitutos, como o periódico e os outros formatos e suportes, conforme a visão de Otlet (1934).

Como lembra Curtius (1996, p.377), o "emprego da escritura e do livro na linguagem figurada ocorre em todas as épocas da literatura universal, mas com diferenças características, condicionadas pela marcha da cultura geral". É interessante observar que, se por milênios o livro foi revestido de um caráter sagrado e nobre, após a revolução científica do século XVIII, tal aura, ao invés de desaparecer, revestiu-se da nobreza e dos rituais de consagração do mundo profano das academias, onde a tese monográfica passou a representar o livro sagrado da pesquisa científica.

Na Grécia antiga, a noção de livro em seu caráter sagrado, bem como a expressão da escritura, recebiam ainda pouca representação simbólica. Segundo Curtius (1996, p.377), o"emprego do sentido figurado da escritura e do livro é desconhecido na poesia grega desde o início. Nem Homero nem Hesíodo o conhecem". Essa negligência está justificada na visão platônica apresentada no Fedro de Platão, que, em certa medida, já inaugura em sua crítica as condições para o simbolismo inerente ao livro.

Será com o Helenismo, e especificamente em Alexandria, que o livro, ou o registro da produção dos saberes do homem, ganha as camadas infinitas de simbolismo. "Agora a criação poética transformou-se em laborioso trabalho noturno de escritório [...] Os epigramas para bibliotecas e seus tesouros tornam-se exercícios poéticos" (Curtius, 1996, p.379). O livro passa a ser tanto a metáfora ideal como a matéria mimetizada do pensamento humano em sua excelência.

No contexto da Biblioteca de Alexandria, o livro "reduz-se ao domínio da filologia e da biblioteconomia, da caligrafia, da bibliofilia e da bibliomania"(Curtius, 1996, p.381). De outro lado, com Plotino, no século terceiro, o livro é visto já tanto como efeito literário (donde se pode vislumbrar o elo retórico por trás de seu simbolismo) quanto como elemento destinado a estimular o conhecimento (donde se pode retirar a raiz filológica) (Curtius, 1996, p.381).

O metaforismo bibliológico puro - o livro como metáfora do mundo, da vida, do homem e do conhecimento - é, desse modo, construído a partir da Antiguidade, passando pelo Medievo, na Cristandade, onde o livro atinge sua "consagração máxima" (Curtius, 1996, p.384), e chegando até a Modernidade, onde a noção de "livro" ganha o significado de liberdade de expressão, haja vista o papel da cultura impressa na Reforma Protestante, com as máquinas miméticas, como a prensa, que permitem sua multiplicação ao inabarcável. Do Livro da Vida do Antigo Testamento (o livro de Deus) ao Livro da Natureza (ou do Mundo) consagrado pelo humanismo da Renascença, ao Livro do Homem da Modernidade científica, da democracia, foi percorrido um período extenso de reinvenção (ou reconsagração) da noção de "livro".

Em 1802, o Dictionnaire daria uma definição simples, com a visão claramente moderna (científica), do conceito de livro:

C'est un écrit d'une certaine étendue, composé par une personne intelligente, pour l'instruction ou l'amusement des lecteurs. II ne faut pas confondre le mot livre avec le mot volume. On entend ordinairement par livre, la totalité d'un ouvrage, et par volume, une partie de cet ouvrage (Peignot, 1802a, p.379, grifo meu).

Em outras palavras, tem-se o livro como a escritura que é resultado de um trabalho intelectual "de uma pessoa inteligente", cujos fins estão na instrução ou no entretenimento. Representa, ainda, uma totalidade. Segundo Otlet (1934, p.9), livro (ou biblión ou document ou gramme) é o termo convencional empregado para 
designar toda espécie de documento. A noção de "livro", entendida assim, responderia por qualquer registro de informação, incluindo o livro propriamente dito, bem como os manuscritos, jornais, revistas, reproduções gráficas, cartas, gravuras, esquemas. No âmbito geral, o livre otletiano indicaria "éléments servant à indiquer ou reproduire une pensée envisageé sous n'importe quelle forme." Essa visão ampla leva o autor a concluir que

Le Livre ainsi entendu présente un double aspect: a) il est au premier chef une oeuvre de I'homme, le résultat de son travail intellectuel; b) mais, multiplié à de nombreux exemplaires, il se présente aussi comme l'un des multiples objets créés par la civilisation et susceptible d'agir sur elle; c'est le propre de tout objet ayant caractère corporelet agencétechniquement (Otlet, 1934, p.9, grifo meu).

Seria necessário um trabalho à parte para a compreensão do "livro"em Otlet, principalmente quando o autor o trata como Livre, em letra maiúscula. A complexidade do conceito está presente em todo o Traité. Em linhas gerais, ele tanto é ordem, como início, meio e fim; conteúdo e continente, como totalidade; o espelho da Bibliologia - antes de ser um campo que estuda o "livro", a ciência bibliológica nada mais é que um dos ramos do próprio Livro.

\section{Conclusão}

Múltiplas questões ainda estão em aberto na análise histórico-filosófica da construção da Bibliologia como macrodisciplina. No solo discursivo brasileiro em $\mathrm{Cl}$ tais questões são ainda mais instáveis, se considerada a baixa representatividade da "palavra" no debate em educação e fundamentação do campo. É fato que a noção de "biblioteconomia" exerce o papel de noção disciplinar até os anos 1980 dentro desse campo, até quando, nos anos 1990, inicia-se a mutação de nomenclaturas que leva à configuração atual do uso da expressão "Ciência da Informação" no contexto da pesquisa em OS. Entre "Biblioteconomia"e "Ciência da Informação", no Brasil, instalaram-se como ponto de inflexão as noções de "bibliografia" e "documentação", fato praticamente inexistente com a palavra "bibliologia".

Dentre as questões nucleares, de fundo conceitual e epistemológico, que permanecem em aberto, destacam-se:
1) o problema crítico do posicionamento da Bibliografia, ora como ciência, ora como teoria, ora como método, quando colocada sua relação com Bibliologia e, por extensão, com os usos de conceitos disciplinares tecidos nos últimos duzentos anos nesse campo. De fato, "primeiro era a Bibliografia", ou seja, o primeiro"conceito-disciplina" do campo foi o neologismo formado pelas palavras gregas biblión e graphein, livro e escrita respectivamente. Biblioteconomia ou ciência das bibliotecas, Bibliologia, Documentação e Ciência da Informação são noções (aplicadas) estritamente mais modernas - na verdade, tecidas do século XVIII para cá;

2) a relação entre francofonia e anglofonia na construção do conceito de "bibliologia", que remete ora à necessidade histórico-semântica pontual de considerar um pensamento francês como autor, se não único, preponderante dessa ciência; ora à necessidade histórico-hermenêutica de perceber o uso epistêmico da noção de "bibliologia" em outros países e línguas e, principalmente, realizar a "anatomia" subdisciplinar e compreender quando e onde a Bibliologia, macrociência, é o nome original dos futuros domínios que advogam para si, no século XX, o direito de afirmar a informação como objeto de estudo.

É preciso perceber que, quando do aparecimento do neologismo "bibliologia", o "livro" que se encontra dentro da palavra não respondia apenas por livros impressos, mas também manuscritos. Do mesmo modo, instituições como "bibliotecas" guardavam coleções extremamente complexas de documentos, para além do códice. No fundo, a noção de "livro"é aberta em demasia, quando vislumbrada na epistemologia bibliológica, e carece de uma abordagem analítica independente. A complexidade da noção de biblión denotava um grupo de significados muito amplos para a relação simples entre livro e códice vegetal, retida como senso comum e, por vezes, como argumento científico. Considerada apenas essa relação superficial dos significados de Bibliologia e de livro, é preciso alertar que, em um sentido histórico-hermenêutico, a Bibliologia vai muito mais além, entre Gabriel Peignot e Paul Otlet, que uma ciência do livro, uma vez que "livro", em ambos, está muito mais além do "códice", sem, em momento algum, deixar de reconhecer seu simbolismo e o poder que ele exerceu e exerce. 
Briet, S. Qu'est-ce que la documentation? Paris: Éditions Documentaires Industrielles et Técnicas, 1951.

Couzinet, $V$. Des pratiques érudites à la recherche: bibliographie, bibliologie. In: Gardiès, C. (Ed.). Approche de l'information-documentation: concepts fondateurs. Toulouse: Cédaduès-Éditions, 2011. p.167-186.

Coblans, H. Introdução ao estudo de documentação. Rio de Janeiro: DASP, 1957.

Curtius, E.R. Literatura européia e idade média latina. São Paulo: Hucitec, 1996.

Day, R. The modern invention of information: Discourse, history and power. Illinois: Southern Illinois University Press, 2001.

Dilthey, W. Introdução às ciências humanas: tentativa de uma fundamentação para o estudo da sociedade e da história. Rio de Janeiro: Forense Universitária, 2010.

Estivals, R. A dialética contraditória e complementar do escrito e do documento. Revista da Escola de Biblioteconomia da UFMG, v.10, n.2, p.121-152, 1981.

Estivals, R. História de la bibliologia. Item: Revista de Biblioteconomia i Documentació, n.11, p.25-41, 1992.

Estivals, R. Paul Otlet dans l'histoire de la bibliologie. Revue de Bibliologie: Schéma et Schématisation, n.73, p.35-42, 2010.

Finó, J.F. Tratado de bibliologia: historia y técnica de produccion de los documentos. Santa Fe: Castellvi, 1954.

Frohmann, B. Revisiting "what is a document?" Journal of Documentation, v.65, n.2, p.291-303, 2009.

Frohmann, B. Documentation redux: Prolegomenon to (another) philosophy of information. Library Trends, v.52, n.3, p.387-407, 2004.

Lovejoy, A.O. A grande cadeira do ser. São Paulo: Palíndromo, 2005

Martinez de Sousa, J. Diccionario de bibliologia y ciencias afines. Editorial Trea, 2004.

Morales López, V. La bibliotecología yestúdios de la información: análisis histórico-conceptual. Cidade do México: UNAM, 2008.
Nietzsche, F. Da retórica. 2.ed. Lisboa: Vega, 1999.

Nietzsche, F. Rhétorique et langage. Paris: Éditions de La Transparence, 2008.

Otlet, P. L'organisation des travaux scientifiques. In: Association Française pour L'avancement des Sciences. Conférences faites en 1919-1921. Proceedings... Paris: Association Française pour L'Avancement des Sciences, 1919. p.15-50.

Otlet, P. Traité de documentation: le livre sur le livre: théorie et pratique. Bruxelas: Editiones Mundaneum, 1934

Peignot, G. Dictionnaire raisonné de bibliologie. Tomo I. Paris: Chez Villier, 1802a.

Peignot, G. Dictionnaire raisonné de bibliologie. Tomo II. Paris: Chez Villier, 1802b.

Revue de Bibliologie: Schéma et schématisation. Paris: Société de Schématologie et de Bibliologie, L'Harmattan, 1968-

Roubakine, N. Introduction à la psychologie bibliologique: la psychologie de la création des livres, de leur distribution et circulation, de leur utilisation par les lecteurs, les écoles, les bibliothèques, les librairies, etc.: théorie et pratique. Paris: Association internationale de bibliologie, 1998.

Saldanha, G.S. Viagem aos becos e travessas da tradição pragmática da Ciência da Informação: uma leitura em diálogo com Wittgenstein. 2008. Dissertação (Mestrado em Ciência da Informação) - Escola de Ciência da Informação, Universidade Federal de Minas Gerais, Belo Horizonte, 2008.

Saldanha, G.S. Uma filosofia da Ciência da Informação: linguagem, organização dos saberes e transgramáticas 2012. Tese (Doutorado em Ciência da Informação) - Instituto Brasileiro de Informação em Ciência e Tecnologia, Universidade Federal do Rio de Janeiro, Rio de Janeiro, 2012.

United States of America. Bureau of Education. Public Libraries in the United States of America: Their history, condition, and management. Part I. Washington: Government Printing Office, 1876.

Wittgenstein, L. Investigações filosóficas. 2.ed. São Paulo: Abril Cultural, 1979. 


\section{ERRATA}

No artigo "A grande bibliologia: notas epistemológico-históricas sobre a ciência da organização dos saberes", com no de DOl: 10.1590/2318-08892016000200006, publicado no periódico TransInformação, v.28, n.2, p.195-207, na página 195:

\section{Onde se lia:}

The great bibliology: Historical-hermeneutic notes on science of knowledge organization

\section{Leia-se:}

The great bibliology: Historical epistemology notes on science of knowledge organization

\section{Na página 198, onde se lia:}

Erudito, bibliógrafo, bibliófilo, interessado nos mais diferentes domínios, Gabriel Peignot, nascido em 1767 e falecido em 1849, escreveu ensaios sobre a liberdade de imprensa no período medieval e no contexto. Seu Dictionnaire Raisonné de Bibliologie, de 1802, propõe-se constituir uma obra didática para os estudos bibliológicos, incluindo a explicação dos principais conceitos do vocabulário que gira em torno do "livro", passando pela indicação de bibliotecas, arquivos, museus, chegando até a exposição dos sistemas bibliográficos aplicáveis às instituições. O autor (tal como fará mais tarde Otlet, interessado em uma visão global sobre a organização dos saberes), também desenvolveu um índice bibliográ-fico universal, em 1812, em que analisa a elaboração e a apropriação dos suportes e técnicas para registro da informação, como pergaminho, papel vegetal, encadernação e litografia. Peignot (1802a, 1802b), tal qual Otlet, atentou ainda para as práticas bibliológicas de maneira ampla, envolvendo os futuros domínios da Museologia e da Arquivologia, além de outros saberes, trabalhando em sua reflexão, por exemplo, com os gabinetes de história natural e física. Por fim, assim como Otlet (1934), o olhar peignotiano considerou a "linguagem" como elemento fundamental e fundacional para a prática do organizador dos saberes: verbetes como "etimologia"e"língua" ganharam exaustividade no trabalho.

\section{Leia-se:}

O autor (tal como fará mais tarde Otlet, interessado em uma visão global sobre a organização dos saberes), também desenvolveu um índice bibliográfico universal, em 1812, em que analisa a elaboração e a apropriação dos suportes e técnicas para registro da informação, como pergaminho, papel vegetal, encadernação e litografia. Peignot (1802a, 1802b), tal qual Otlet, atentou ainda para as práticas bibliológicas de maneira ampla, envolvendo os futuros domínios da Museologia e da Arquivologia, além de outros saberes, trabalhando em sua reflexão, por exemplo, com os gabinetes de História Natural e Física. Por fim, assim como Otlet (1934), o ol har peignotiano considerou a"linguagem" como elemento fundamental e fundacional para a prática do organizador dos saberes: verbetes como "etimologia"e "língua" ganharam exaustividade no trabalho. 